HERNIOTOMY PLUS LAPAROTOMY SUCCESSFULLY PERFORMED UNDER VERY UNUSUAL AND DIFFICULT CIRCUMSTANCES.

BY E. MATTHEWS OWENS, M.D., L.R.C.P. EDIN., M.R.G.S. ENG.

IT is to be sincerely hoped that it will but seldom occur to a surgeon to be placed in the position in which $I$ was on Sept. 8th, 1898, when on board the s.s. Nincveh, belonging to the Aberdeen White Star Line, while off the Cape.

The patient, a steerage passenger, thirty-eight years of age, when lifting a box in a strong gale of wind at 4 P.M. strangulated an old inguinal and scrotal hernia. I tried gentle taxis, ice, opium, and other usual remedies, but all to no purpose. I felt assured that an operation would be required and therefore $I$ was very careful about taxis, not using more pressure than was absolutely necessary. At 8 P.M. I decided to operate, knowing full well that every hour would lessen the chance of success and the man was rapidly losing strength, vomiting being incessant and the pain excruciating. The rôle of anæsthetist I had to entrust to the purser (Mr. Freeman). In reply to my inquiries he said that he had seen chloroform given once and that he was "not afraid"; so I rejoined, "You will do." There was on board the usual amputation case which was of no use in this operation and there was also a pocket dressing-case. The latter had to supply all the instruments; it contained, luckily, a finger amputation knife. In the amputation case was a Wells's forceps of primitive pattern. The silk used was of the usual braided kind wound on a card and not too clean. I raked up six needles such as are to be found in pocket-cases and are used for sewing up superficial cuts. There were no sponges, but about $\frac{1}{4} \mathrm{lb}$. of alembroth wool as well as plenty of lint. Fortunately there was a bottle of iodoform gauze. For antiseptics I had to depend upon a bottle of solution of perchloride of mercury (B.P.) and boric acid, the latter being not too plentiful. Empty beer-cases and a mattress were made to serve as a couch, and the operating theatre was the surgeon's cabin, the available space of which was $6 \mathrm{ft}$. by $5 \mathrm{ft}$. $6 \mathrm{in}$. The patient's feet were against the door and his head was against the bunk. I thought of the theatre of St. Mary's Hospital where I had spent so many happy and profitable hours during the previous twelve months watching my old friends Owen, Page, and Pepper doing such brilliant things. If they could only have seen $m y$ theatre and instruments and assistants! For assistants I had to have two deck hands, whose sole duty was to keep the patient from rolling off his by no means safe couch, and in spite of every care we were hurled from side to side by the rolling, and more than once assistants, patient, anæsthetist, and operator were generally mixed up when an extra big sea hit the ship. The patient having been brought under the influence of the chloroform I again tried taxis with no benefit. After shaving the pubes and disinfecting the skin as well as I could I cut down over the sac which I rapidly opened and I divided the stricture (in the pocket-case there was a hernia knife). A " mixing up" such as I have referred to above then took place and when we had got back into our respective places $I$ found that from 12 in. to $15 \mathrm{in}$. of intestines had come out of the scrotum (it was a big hernia). Then another interruption, a mere matter of detail, occurredviz., artificial respiration had to be performed, the anæsthetist having been too liberal with his chloroform. That being successful I was again at liberty to resume my operation, but having no sponges and no assistants to look after the exposed bowel it had to take its chance whilst I was at the other work. That "chance" was not very bright, I thought, for the bowel was not too warm. I now tried to return the gut into the abdominal cavity, but do what I would I could not coax it back. There were no adhesions at the stricture, but the cause of my not being able to get it back was the presence of so much flatus. I was at my wit's end with not a soul to consult and with no friendly colleague to offer a suggestion. I decided to perform laparotomy and to draw the bowel from the inside. I made my incision 4 in. in length in the middle line. There was a large amount of venous bleeding from the engorged abdominal vessels which I could only control with hot water. When this had been stopped I oponed the peritoneum and passed my hand within the abdomen and by gentle manipulation from without and within $I$. was able to pass the flatus on and thus get the bowel back into the abdominal cavity. The sewing up of the abdominal wound presented some difficulty, the needles being so short and the abdominal walls thick, and as there was no needle-holder the hasulle of the shut-up finger-knife had to be used to push the needle on, Wells's forceps doing the rest. $i$

I thought that if the poor fellow 1 ved I should like his hernia to be radically cured, but how on earth was I to get the pillars of the ring together? For I most ccrtainly did not care to bury sutures with such silk as I was using, so I determined to gather the edges of the pillars like a purse, using one piece of thick silk armed with two of my little needles. After gathering it up I brought both needles out through the skin half an inch apart and an inch or so from the wound and tied the suture tightly. The result was most satisfactory for the parts became thoroughly consolidated.

The after-treatment consisted chiefly of the patient being rolled from side to side by the motion of the vessel for four days for it blew hard all that time, but in spite of everything against him his temperature never reached $99^{\circ} \mathrm{F}$. and on Sept. 28th he walked off the steamer at Melbourne quite well. I heard from him from Tasmania on Oct. 24th that " he never was in better health, that the wounds were only faint red lines, and that he felt nothing whatever of his rupture."

Now, there is no use in publishing cases unless there is some lesson to be learnt, and what does this case teach? Firstly, to remember that in the majority of cases of strangulated hernia taxis will not be successful; therefore taxis should be used as little as possible and as gently as possible, for if operation is dispensed with for the time being it will have to be resorted to at some future time and the operator then will not be inclined to bless the practitioner who has made the patient run greater risk for the useless and perhaps rough manipulation which the bowel has received at his hands. Secondly, operation should be performed early. This man owed his life to the fact that I used but gentle taxis and that I operated within four hours of the strangulation, so that he was not allowed to get exhausted by vomiting and pain, when knowing full well that I should have to relieve him sooner or later by operative measures. Thirdly, never despair of, or "funk," an operation however black things look against its chances of success.

Bencligo, Victor in, Lustralia.

\section{A CASE OF CONGENITAL ABSENCE OF BOTH CLAVICLES.}

By GUSTAVE SCHORSTEIN, M.B. OxON., F.R.C.P. LoND., D.P.H.,

ASSISTANT PHYSICIAN TO THE LONDON HOSPITAL

A GIRL, aged thirteen years, was brought to see me at the London Hospital with a history of losing weight and of sickness in the morning. Her picture appears at Fig. 1 of the accompanying plate. She was rather small and dark-skinned. The father and mother are both healthy and there are three brothers who are also healthy. There is no evidence of tuberculosis or of syphilis in the family. The child has always been weakly. She was "rickety" as an infant and could not walk till she was four years old. She has had measles and had at the age of nine years a long illness with fever and diarrhoea which may have been enteric fever. The patient is small in height and size, the height being $4 \mathrm{ft}$. 2 in. She is very dark in colour. The head is out of proportion to the body but not overlarge for her years. The frontal and parietal eminences are prominent and the depression between the frontal eminences is well marked. The fontanelles have closed. There is a large depression corresponding to the anterior fontanelle and a smaller one corresponding to the posterior fontanelle. The mother stated that the anterior fontanelle did not quite close till the child was nine years old and for that reason she was anxious when sending her to school. The conjunctivæ are very pale and there is slight general anæmia. There is some enlargement of the glands in front of the left sterno-mastoid.

On examining the front of the chest there is no very obvious 







Fig. 1.
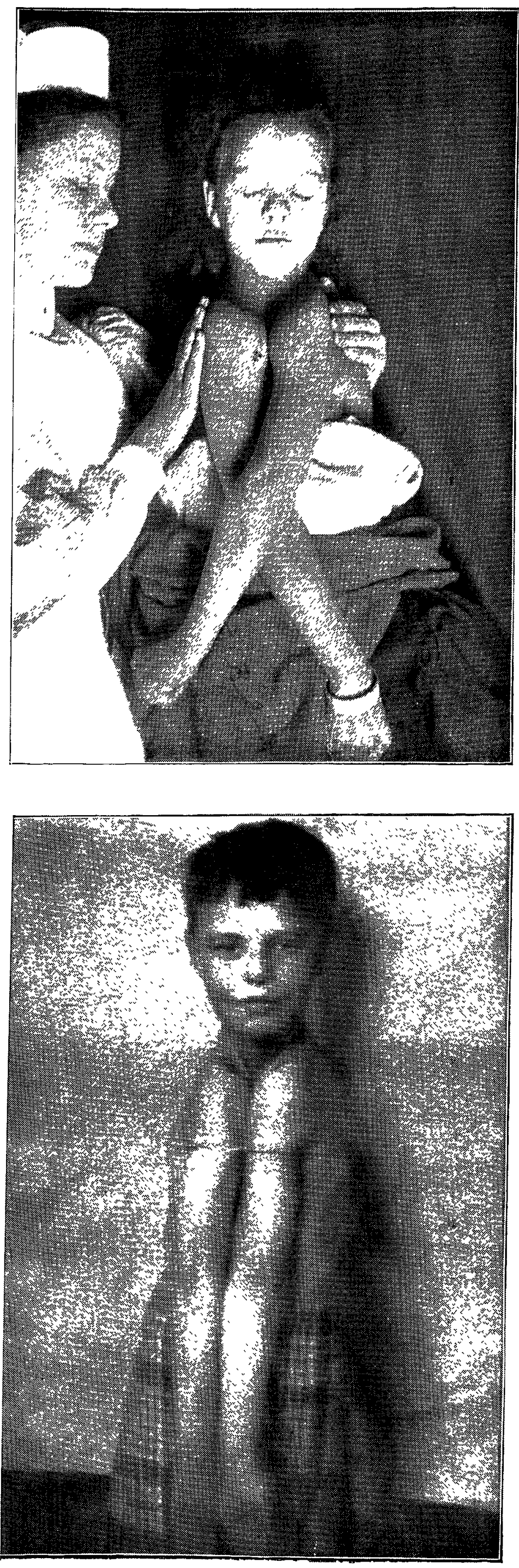

Fig. 3.
Figr 2 .
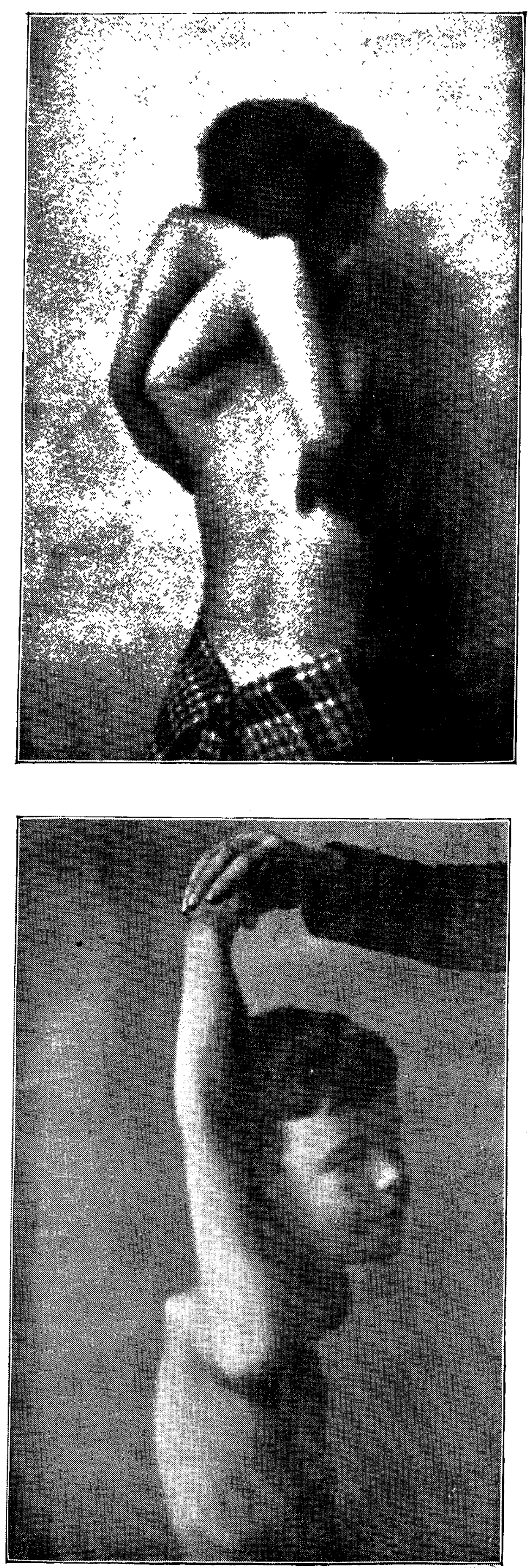

Fig، 4,

TO ILLUSTRATE PAPERS BY DR. G. CARPENTER AND DR. SCHORSTEIN. 
abnormality when the child stands still. The shoulders droop slightly and fall forwards a little and there is a continuous surface on either side in front and above, in place of distinct supra- and infra-clavicular fossæ. The thorax itself is fairly well shaped, with a little depression of the sternum backwards. On drawing the finger along the site of the clavicle on either side it is found that the outer two-thirds of both clavicles are absent. On the right side this is not absolutely true, as there is a small spicule of bone about $\frac{2}{5}$ in. in length articulating with the right acromion. (This is shown in the skiagram.) The inner thirds of both clavicles are present; they articulate apparently by a good joint with the sternum and end externally in a fairly sharp point immediately uncler the skin. This piece seems to be fibrous or cartilaginous and not bony, and does not show in the skiagram. To it on each side is attached the clavicular portion of the sternocleido-mastoid muscle, both of which are perfectly developed. On turning the head to the opposite side, and pulling on the clavicular head of the sterno-cleido-mastoid, the external end of the clavicle present is made prominent. The first rib and the attachment of the scalenus anticus muscle can be easily mapped out and the subclavian artery compressed on the upper surface of the first rib. There is no cervical rib. On examining the back, the scapulæ are in the alar position. The scapule are small and at first give the impression that there is no supraspinous fossa; but there is on either side a small supraspinous fossa and a supraspinatus muscle.

The arms and legs are small but are fairly shaped and not bent. All the joints are good. The teeth are much decayed, the enamel of the free edges of the upper central incisors is irregular, but in shape and appearance the teeth do not suggest syphilis. There is no grave abnormality of the heart or lungs. The liver and spleen are normal in size The urine is normal. There are no changes in the media of the eyes or in the retina or choroid. Except for some anæmia the child was perfectly well during her stay in hospital.

The two points of interest in the case are: (1) the singularly little amount of inconvenience produced by the absence of the clavicles and (2) the pathology of the condition. The amount of inconvenience was so small that neither the patient nor her mother was aware of anything odd until it was pointed out to them. On examination it was found that there was practically no ordinary movement which the child could not carry out well. She can lift a heavy weight right above her head with ease. She can give a fairly heavy blow from the shoulder and can lift her "oody when suspended by the arms. The additional freedom of movement enables the two acromion processes to be brought into contact anteriorly in the middle line, as shown in the photograph (Fig. 1 in inset), and allows her to twist her arms behind her back much more readily than usual.

The condition is a rare one. A precisely similar case (with engraving) is recorded in the Archiv für Heilkunde by 0 . Kappeler, who gives references to four somewhat similar cases recorded by C. Gegenbauer. Most interesting from the pathological standpoint is a record of the only two postmortem examinations of similar cases which $\mathbf{I}$ can find which is given by Professor Scheuthauer ${ }^{2}$ of Budapest. In all the accounts absence of clavicles and particular conformation of the head seem to go together. Professor Scheuthauer's records are both of adults. He describes the large frontal and parietal eminences with deep grooves between. The anterior and posterior fontanelles were not fully closed in either of his cases. The bones of the vault of the skull were thin and porous. He found on dissection that all the muscles in the neighbourhood of the clavicle were properly developed in spite of the absence of the bone and this certainly appears to me to be the case in my patient. "The clavicular portions of the right and left deltoid and trapezius muscles are inserted into an oblique band of fibrous tissue which starts near the upper end of the sternum, runs across in front of the glenoid fossa of the scapula, and terminates in an angular piece of bone 1 in. long, slightly convex, close to the upper part of the fossa. To the upper portions of this band the clavicular portion of the sterno-cleido-mastoid muscle is attached; to the lower the pectoralis major. From its lower surface springs a very large subclavius muscle. The costo-coracoid membrane fuses with it." In one of the cases there were sternal rudiments of the clavicle, as in my patient. He notes the smallness of the nasal bones and of the temporal portion of the temporal bones.

It is at once obvious that the bones which are undeveloped are all bones (clavicles, frontal, parietal, occipital, nasal) which develop in membrane. The two possible underlying factors are foetal syphilis and fotal rickets. Of syphilis in my patient I can find no history whatever and absolutely nothing confirmatory in the eyes, teeth, or viscera. Still it may later prove that it is an expression of syphilis. The abnormality in the clavicle and the skull appears to me to be the result of rickets showing itself before the end of the second month of fœtal life. The story of the very late age (four years) at which the child learnt to walk and the late closure of the anterior fontanelle (nine years) fit in with this hypothesis.

I am indebted for the photographs to Mr. Ernest Harnack of the London Hospital.

Portlant-place, $W$.

\section{A CASE OF ABSENCE OF THE CLAVICLES,}

WITH AN ACCOUNT OF VARIOUS DEFORMITIES OF THE CIASICLES IN FIVE OTHER MEMBERS OF THE SAME FAMILY.

BY GEORGE CARPENTER, M.D., M.R.C.P. LoND., SENIOR PHYSICIAN TO OU'L-PATIENTS AT THE kVELIYA HOSPITAL FOH SICK CHILDREN.

A GIRL, aged eight years, was brought to the Evelina Hospital for Sick Children on Nov. 22nd, 1897, suffering from impetigo contagiosa with secondary glandular implication. While making a physical examination a deficiency of clavicles was discovered. Her mother then volunteered the information that a brother had a similar deformity on one side. The child's father also had a deformity of the clavicle and a depression of the lower part of the sternum and two sisters older than herself had club feet. Another child, an out-patient, was found to have a depression in the middle of the sternum. Examination revealed the following abnormalities. The clavicles were represented by two small fragments, thin, tapering, and cartilaginous (the Roentgen photograph suggests bony as well), attached by their broader extremities to the sternum. The left was longer than the right, their respective lengths being $1 \frac{1}{4}$ in. and $\frac{3}{4}$ in. On the index finger being pressed behind the outer extremity of either fragment the fragments could be dislocated so that their direction was nearly straight forwards. In this position a depression of the lower part of the sternum was evideut and the sternum was seen to be unusually wide at its upper part. As the child stood upright the shoulders were obviously narrowed; they fell downwards and forwards, the scapular angles projected backwards to a marked extent, and under the acromion was seen a depression as in a sub-glenoid dislocation. What appeared to be the first rib could be felt with great distinctness on either side, as also the coracoid processes. Between each coracoid process and acromion was a well-developed coraco-acromial ligament, and so apparent were these ligaments that they raised the suspicion of acromial elavicular fragments. The sterno-mastoid muscles apparently had some attachments to the fragmentary sternal clavicles. The clavicular portions of the great pectoral muscles were wanting, but the pectoral portions stood out well when placed in action. The anterior portions of the deltoid muscles were also wanting, as also were the clavicular fibres of the trapezius muscles. The child was thin and her muscles were not well developed, but she was not by any means wanting in power. She could carry the youngest child, a well-developed infant a year old, could push and throw well, and could bear the weight of her body when hanging by her hands. She could approximate her shoulders to an extraordinary extent with the greatest ease. Another position (Fig. 2) was assumed and retained with the greatest ease. Here the arms were crossed behind the head, the elbows pointed upwards, and, as may be seen, were several inches apart. The scapular borders could be made to touch behind and even to overlap. By 